\title{
Long-pulsed ruby laser-assisted hair removal in male-to-female transsexuals
}

\author{
P Paquet, I Fumal, C Piérard-Franchimont \& G E Piérard
}

Department of Dermatopathology, Unit of Dermocosmetology, University Medical Center Sart Tilman and Sauvenière, Liège, Belgium

\begin{abstract}
Summary
Background Unwanted male-pattern pilosity is a heavy psychological burden and can cause distress for male-to-female transsexuals. Orchidectomy and oestrogen supplementation combined with antiandrogens fail to make hair disappear.

Aims To study the effect of long-pulsed ruby laser treatment.

Results Hair density was successfully abated on the beard and chest of three male-tofemale transsexuals. A lingering effect over 6 months with a 50-90\% hair density reduction was obtained.

Conclusion Photothermolysis using the long-pulsed ruby laser is a promising, well-tolerated method of hair removal in male-to-female transsexuals under oestrogen supplementation and antiandrogens.
\end{abstract}

Keywords: hair removal, laser, photothermolysis, transsexual

\section{Introduction}

Unwanted male-pattern pilosity, especially the beard, is a heavy burden for male-to-female (M-F) transsexuals who request hormonal induction of secondary sex characteristics of the opposite sex. This leads to severe psychosocial distress in some subjects. Years after orchidectomy, the beard continues to grow because oestrogen supplementation and antiandrogens have little effect on male-pattern hair growth. ${ }^{1,2}$ Camouflage and physical methods for masking continuous hair growth, including shaving, plucking, waxing, bleaching and chemical depilatories are cosmetically unsatisfactory. ${ }^{3}$ They can induce side-effects like folliculitis or contact allergic reactions. Electrolysis is a tedious, painful and time-consuming procedure, nearly impossible to perform successfully on large areas such as the beard and chest. ${ }^{3}$

Laser-assisted hair removal might appear to be an attractive option in M-F transsexuals because it is rapid, allowing the treatment of large areas with minimal risk of adverse

Correspondence: Dr P Paquet, Department of Dermopathology, Unit of Dermocosmetology, University Medical Center Sart Tilman and Sauvenière, B-4000 Liège, Belgium. E-mail: P.Paquet@chu.ulg.ac.be

Accepted for publication 19 September 2001 effects. ${ }^{2}$ Selective photothermolysis can be achieved by long-pulsed ruby, Q-switched Nd-yag, alexandrite, diode lasers and by intense pulsed light source. ${ }^{3-5}$

We treated three M-F transsexuals presenting unwanted hair growth on the beard and chest using a normal mode long-pulsed ruby laser. Patients were evaluated clinically. In addition, the hair diameter and density were measured before and after the laser treatment.

\section{Materials and methods}

Three M-F transsexuals were treated on different anatomic sites for hair removal using a long-pulsed ruby laser. The salient clinical characteristics are summarized in Table 1. The ruby laser (Rubystar ${ }^{\circledR}$, Aesculap Meditec, Germany) was used in the free-running, long-pulse mode. The laser emitted $2 \mathrm{~ms}$-pulses at $694 \mathrm{~nm}$ wavelength, at up to $1 \mathrm{~Hz}$, with a maximal fluence of $13 \mathrm{~J} / \mathrm{cm}^{2}$ and a $10-m m$ diameter target circle. This unusual broad size of the spot was much larger than that of other lasers. It entailed a decreased fluence while permitting deeper light penetration and increased energy delivery to hair by reducing light scattering outside the target. 6

Prior to laser treatment, the skin was shaved to prevent absorption of laser light. To ensure optimal penetration of 
Table 1 Male-to-female transsexuals treated for hair removal by long-pulsed ruby laser.

\begin{tabular}{|c|c|c|c|c|c|}
\hline $\begin{array}{l}\text { Patients and } \\
\text { laser-treated site }\end{array}$ & Age (years) & Hair colour & Skin phototype & Medical treatment & $\begin{array}{l}\text { No of } \\
\text { laser sessions }\end{array}$ \\
\hline $\begin{array}{l}1 \\
\text { Beard }\end{array}$ & 50 & Black & $\|$ & $\begin{array}{l}\text { Orchidectomy (1994) } \\
\text { Oestradiol benzoate } \\
\text { Oestradiol propionate }\end{array}$ & 8 \\
\hline $\begin{array}{l}2 \\
\text { Beard }\end{array}$ & 27 & Black & $\|$ & $\begin{array}{l}\text { Oestradiol benzoate } \\
\text { Oestradiol propionate } \\
\text { Cyproterone acetate }\end{array}$ & 6 \\
\hline $\begin{array}{l}3 \\
\text { Chest }\end{array}$ & 40 & Black & $\|$ & $\begin{array}{l}\text { Orchidectomy (2000) } \\
\text { Oestradiol, } \\
\text { Cyproterone acetate }\end{array}$ & 6 \\
\hline
\end{tabular}

the beam and reduce heat diffusion to the surrounding skin, a thin layer of fresh optical coupling gel was applied $1 \mathrm{~min}$ before starting the laser treatment. To reduce the post-treatment inflammatory reaction, cooling-packs were applied for $5 \mathrm{~min}$ on the treated sites followed by daily topical applications of a corticosteroid cream for one week. As hair cycles are longer on the trunk than on the face, therapy sessions took place at 2 month intervals for the chest and at 1 month intervals for facial hair. The treatment end point was the patient's satisfaction based on personal wishes and comparative examination of photographs.

Standardized clinical photographs (Dermaphot ${ }^{\circledR}$, Heine Optotechnik, Germany) were taken on $9 \times 12 \mathrm{~mm}$ fields before the first treatment and 6 months after the last treatment. Hairs were counted on the printed photographs to calculate hair density per $\mathrm{cm}^{2}$.

At least 5 hairs were plucked before initiating the treatment and after the fifth laser session. These samples were placed onto a glass slide using double-sided tapes and examined under the microscope. The most proximal hair diameter was measured using a micrometer device.

\section{Results}

The laser treatment was relatively painful, especially on the face. However, local anaesthesia was not required. A moderate to severe erythema occurred immediately after each treatment session, lasting for a couple of hours up to a few days. Occasionally, small crusts developed, resolving in about one week. No severe side-effect such as hypo-hyperpigmentation, erosion, purpura or scarring was noted. Clinical photographs showed impressive waning in hair density in the three patients. The improvement still persisted 6 months after the last treatment without any significant regrowth. In one patient, only rare terminal hairs were still visible (Fig. 1a,b). The two other patients experienced hair reduction reaching $75 \%$ and $50 \%$ respectively (Fig. 2a,b).
The mean hair diameter was larger on the face than on the chest. On the beard area, it remained similar before initiating the laser treatment and after the last treatment session. By contrast, it decreased markedly on the chest (Table 2).

\section{Discussion}

Persistence of male-pattern pilosity is a major complaint in M-F transsexuals, considerably affecting the social life and sometimes leading to psychological distress. ${ }^{1,2}$ To maintain a female status, M-F transsexuals are supplemented by oestrogen plus antiandrogens that aim to hinder androgen action. Unfortunately, orchidectomy and hormone therapy, even at high doses, exhibit only a moderate effect on hair growth. ${ }^{1,2}$ Oestrogen plus antiandrogen administration decreases hair diameter, but hair length is relatively preserved in androgen deprivation, pointing to different regulations in hair length and width. ${ }^{1}$ In M-F transsexuals, male-pattern hair growth remains substantial in spite of rapid and considerable suppression of circulating serum androgens. ${ }^{1}$ Indeed these hormones are not necessary to sustain some degree of male-pattern hair growth once it has been established and even androgendependent hirsutism seems to be largely antiandrogen resistant. ${ }^{1,2}$

Androstanediol glucuronide is a marker of androgen metabolism in peripheral tissues. ${ }^{7,8} \mathrm{~A}$ decreased serum level in this hormone is only weakly associated with changes in hair growth, indicating that androgen receptor and postreceptor mechanisms play an important role in the sex steroid sensitivity of the pilosebaceous unit. ${ }^{1}$ As hormone therapy is not recognized to be sufficient to provide a significant improvement in the pilosity of M-F transsexuals, other methods of destroying unwanted hairs should be considered. Intense pulsed light source and laser hair removal are now the more realistic treatment options since they provide a quick, efficient and relatively comfortable modality permitting treatment of large areas of skin..$^{3,4}$ 

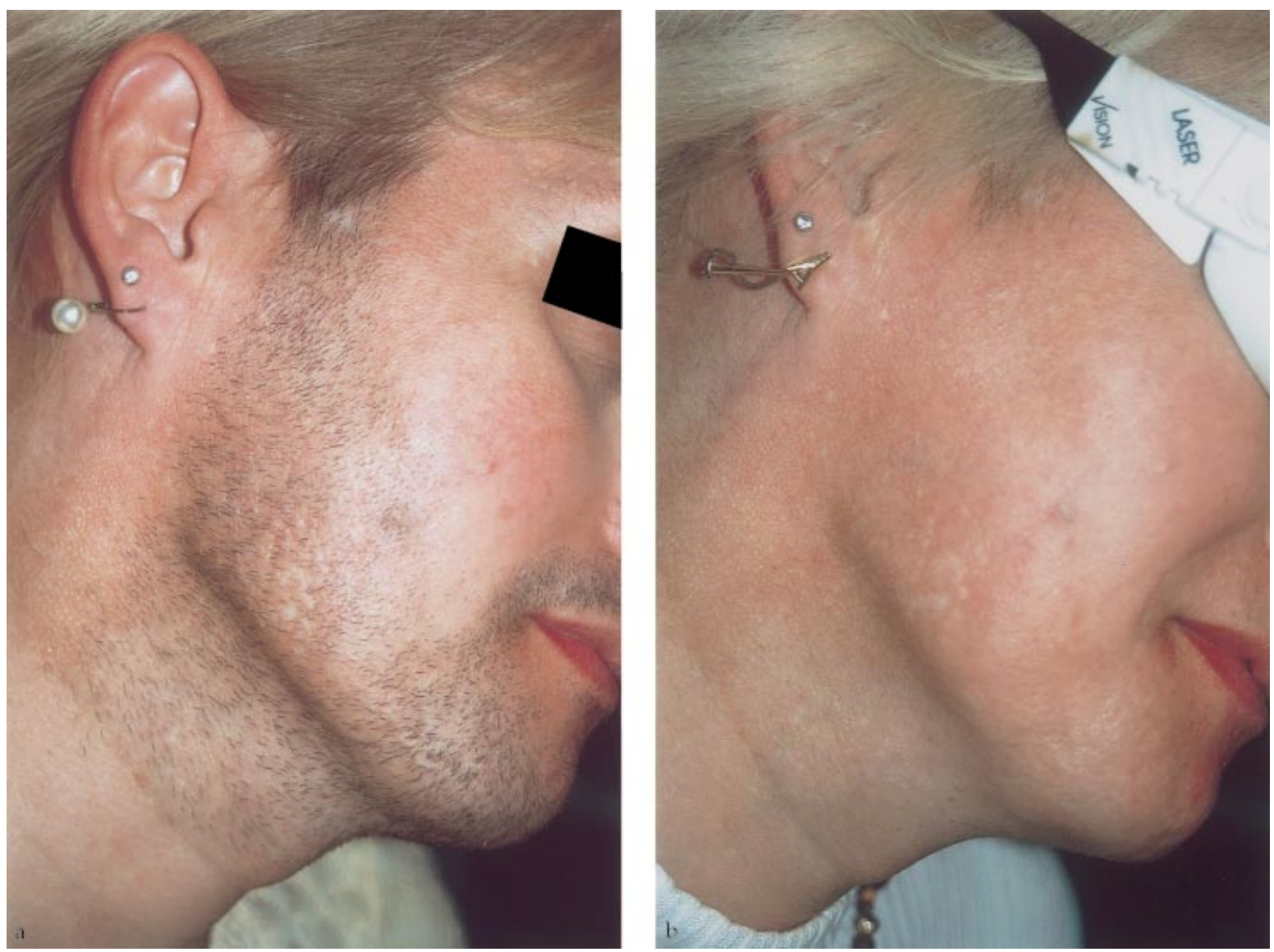

Figure 1 Ruby laser-assisted hair removal of the beard in patient 1, (a) before treatment and (b) 6 months after 8 sessions of treatment.

Table 2 Hair charateristics in 3 male-to-female transsexuals.

\begin{tabular}{|c|c|c|c|c|}
\hline \multirow{2}{*}{$\begin{array}{l}\text { Patient and } \\
\text { treated site }\end{array}$} & \multicolumn{2}{|c|}{ Terminal hair density (number/ $\mathrm{cm}^{2}$ ) } & \multicolumn{2}{|c|}{ Mean terminal hair diameter $(\mu \mathrm{m})$} \\
\hline & Before initiating treatment & After treatment & Before initiating treatment & After treatment \\
\hline 1 , beard & 27 & 2 & 113 & 109 \\
\hline 2 , beard & 51 & 14 & 131 & 128 \\
\hline 3 , chest & 15 & 7 & 93 & 74 \\
\hline
\end{tabular}

Several laser-assisted hair removal devices, including ruby, alexandrite, diode and Nd-yag lasers induce selective photothermolysis of hair. ${ }^{3-5}$ Some intense pulsed light sources have also been used successfully. ${ }^{3,4}$ It is acknowledged that dark hair responds considerably better to these treatments than fair hair. We currently use the normal mode (long-pulsed) ruby laser because it penetrates deeply into the skin and effectively destroys the melanincontaining follicular epithelium by selective photothermolysis using melanin as the target chromophore. ${ }^{9,10}$ Using optimal clinical conditions (fair complexion, adapted fluence) no infection, scarring, and long-term complication occurred. In our M-F transsexual patients, a major reduction in black hair density occurred on the face and on the chest (90, 75 and 50\%), following a limited number of treatments. The beneficial results persisted at least 6 months after the last laser session, with only a slight scattered regrowth. The achieved results cannot be considered permanent and some maintenance treatment is anticipated.

The most prominent beneficial effect of the ruby laser occurred on the face. It is possible that laser-assisted 


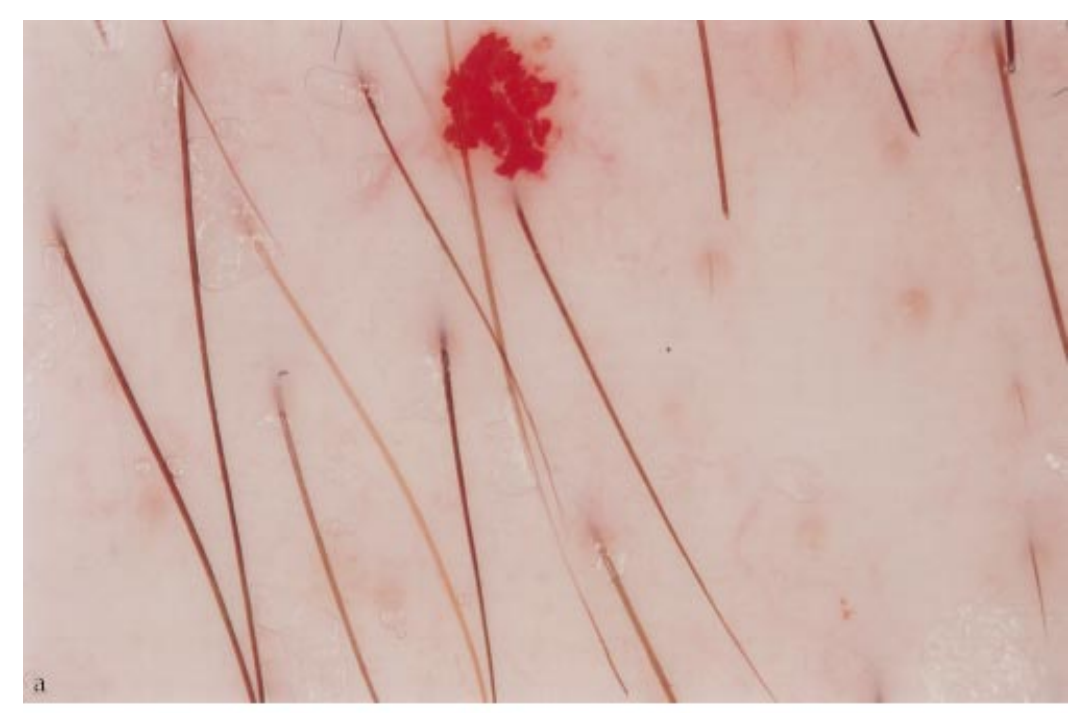

Figure 2 Terminal hair density on the chest in patient 3, (a) before treatment and (b) 6 months after 6 sessions of treatment.

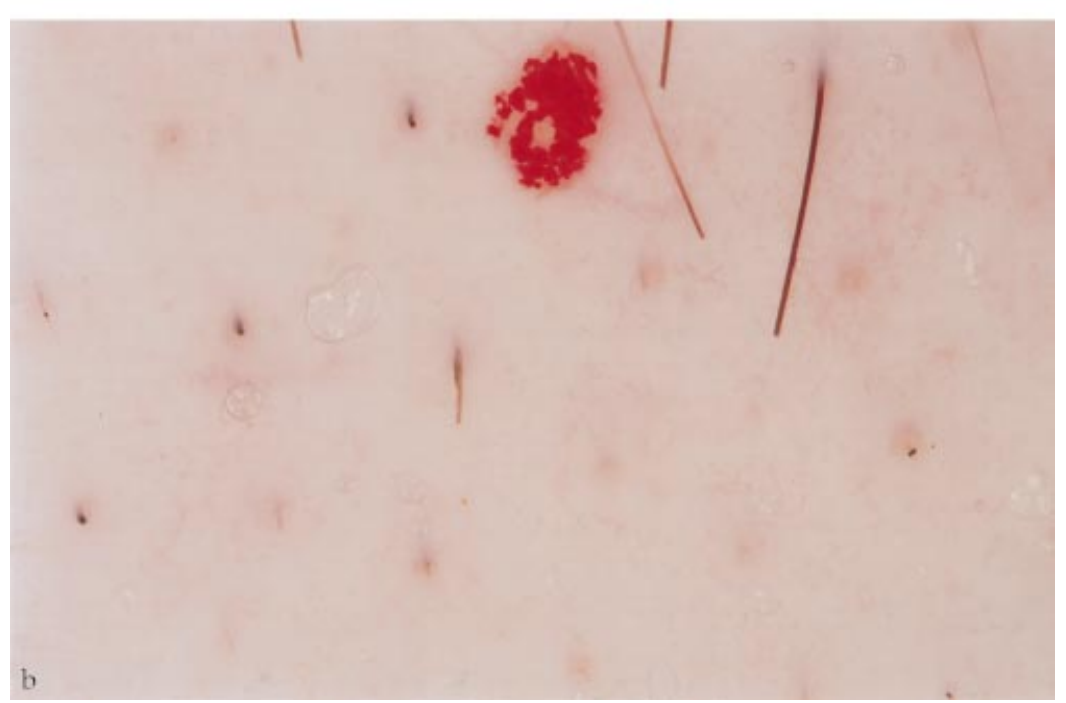

hair removal targets preferentially thicker hair because they have a higher melanin content and lose heat more slowly than thinner hair. ${ }^{11}$ Thus heat persists adjacent to the viable components of the thicker hair follicules for a longer time. However, the hair diameter on the face did not decrease with the treatment sessions. By contrast, there was a significant reduction in hair diameter of regrowing hair at laser-treated sites on the chest. This has important clinical implications because despite regrowth of thinner hair, it often improves the unwanted visual appearance. The mechanism underlying this phenomenon and its persistence are currently unknown. It may be due to the partial destruction of the germinative cell compartment that gives rise to new hair formation.

\section{Conclusion}

In conclusion, orchidectomy, oestrogen replenishment and potent antiandrogen treatments are not sufficient to abate male-pattern pilosity in M-F transsexuals. The long-pulsed ruby laser provides a quick, efficient and relatively comfortable method of long-lasting epilation in patients with black hair.

\section{References}

1 Giltay EJ, Gooren JG. Effects of sex steroid deprivation / administration on hair growth and skin sebum production in transsexual males and females. J Clin Endocr Metab 2000; 85: 2913-21. 
2 Raulin C, Werner S, Hartschuk W, Schönermark M. Effective treatment of hypertrichosis with pulsed light: a report of two cases. Ann Plast Surg 1997; 39: 169-73.

3 Liew SH. Unwanted body hair and its removal: a review. Dermatol Surg 1999; 25: 431-9.

4 DiBernardo BE, Perez J, Usal H, Thompson R, Callahan L et al. Laser hair removal: where are we now? Plast Reconstr Surg 1999; 104: 247-57.

5 Raulin C, Greve G. Temporary hair loss using the longpulsed alexandrite laser at 20 milliseconds. Eur J Dermatol 2000; 10: 103-6.

6 Lask G, Elman M, Slatkine M, Waldman A, Rozenberg Z. Laser-assisted hair removal by selective photothermolysis. Dermatol Surg 1997; 23: 737-9.

7 Horton R, Hawks D, Lobo RA. $3 \alpha, 17 \beta$-androstanediol glucuronide in plasma, a marker of androgen action in idiopathic hirsutism. J Clin Invest 1982; 69: 1203-6.

8 Rittmaster RS. Androgen conjugates: physiology and clinical significance. Endocr Rev 1993; 14: 121-132.

9 Polderman M, Pavel S, Le Cessie S, Grevelink J, Van Leeuwen R. Efficacy, tolerability, and safety of a long-pulsed ruby laser system in the removal of unwanted hair. Dermatol Surg 2000; 26: 240-3.

10 Gault DT, Grobbelaar AO, Grover R, Liew SH, Philip B. et al. The removal of unwanted hair using a ruby laser. Br J Plast Surg 1999; 52: 173-7.

11 Liew SH, Ladhami K, Grobbelaar AO, Gault DT, Sanders R. et al. Ruby laser-assisted hair removal reduces the coarseness of regrowing hairs: fallacy or fact? Br J Plast Surg 1999; 52: 380-4. 